\title{
Responsabilidad fiscal de los interventores. Análisis del dolo y la culpa grave
}

\section{Fiscal liability of the controllers. Analysis of dolo and grave guilt}

\author{
DOI: https://doi.org/10.17981/juridcuc.17.1.2021.04
}

Fecha de Recepción: 2019/12/09 Fecha de Aceptación: 2020/09/24

Luis Carlos Gil Cadavid

Contraloría General de la República. Bogotá, D.C. (Colombia)

eleryxo@hotmail.com

\section{Uriel Ángel Pérez Márquez}

Corporación Corporación Universitaria Rafael Núñez. Cartagena (Colombia) perezmarquezconsultores@gmail.com

Para citar este artículo:

Gil, L. y Pérez, U. (2021). Responsabilidad fiscal de los interventores. Análisis del dolo y la culpa grave. Jurídicas CUC, 17(1), 87-118. DOI: http://dx.doi.org/10.17981/juridcuc.17.1.2021.04

Resumen

Se trata en esta oportunidad de una respuesta a un proyecto investigativo que reflexiona acerca de la prueba del dolo y culpa grave de los interventores contractuales en procesos de responsabilidad fiscal, a partir de la revisión analítica de decisiones emanadas de la Contraloría General de la República -Gerencia Bolívar-, en el período de gerencia 2012-2018. Su objetivo general fue analizar la forma como se ha aplicado a los interventores contractuales, el sistema probatorio subjetivo, en los procesos de responsabilidad fiscal adelantados por esta institución. Para tales fines se desarrolló una investigación jurídica, de enfoque cualitativo y tipo documental, haciendo uso del método hermenéutico. En consonancia con ello, la técnica predominante fue el análisis documental y la triangulación hermenéutica de los resultados. Se presenta así una exposición de casos legales, que constituyen una muestra de procesos de esta entidad que habiendo iniciado bajo la Ley 1474 de 2011, fueron fallados antes de culminar el segundo semestre de 2018, en todos ellos se vinculó al interventor como presunto responsable fiscal.

Palabras clave: Culpa grave y dolo; Principio de Responsabilidad y Solidaridad en la contratación pública; Responsabilidad Fiscal

\section{Abstract}

This time it is a response to an investigative project that reflects on the proof of intent and gross negligence of contractual auditors in fiscal responsibility processes, based on the analytical review of decisions issued by the General Comptroller of the Republic -Management Bolívar-, in the management period 2012-2018. His general objective was to analyze the way in which the subjective evidence system has been applied to the contractual auditors in the fiscal responsibility processes carried out by this institution. For these purposes, a legal research was developed, with a qualitative and documentary approach, making use of the hermeneutical method. In line with this, the predominant technique was documentary analysis and hermeneutical triangulation of the results. Thus, an exposition of legal cases is presented, which constitute a sample of processes of this entity that, having started under Law 1474 of 2011, were ruled before the end of the second semester of 2018, in all of them the controller was linked as allegedly responsible fiscal.

Keywords: Fiscal Responsibility; Principle of Responsibility and Solidarity in public procurement; Serious fault and intent 


\section{INTRODUCCIÓN}

El rango de aplicación del principio de responsabilidad de los interventores se ha ido expandiendo de manera gradual en las normas que regulan la contratación pública en Colombia. Un importante cambio fue introducido por la Ley 1474 (2011, art. 82, inc. 2; art. 119), al modificar la Ley 80 (1993, art. 53), que amplió el contenido de responsabilidad de los supervisores e interventores de contratos estatales, estableciendo ahora que serán responsables civil, penal, fiscal y disciplinariamente. Además, el parágrafo tercero del mismo artículo señala que el interventor será responsable solidario de los daños que se ocasionen por el incumplimiento del contrato vigilado, si éste no hubiere notificado a la Entidad de manera oportuna. Sin embargo, no puede entenderse en materia de Responsabilidad Fiscal que esta modificación indique el establecimiento de un régimen de responsabilidad objetiva para los interventores y que solo será necesaria la prueba de la culpa grave del contratista para que junto con la suya se colija la del interventor.

A partir de lo anterior, se planteó la pregunta problémica del proyecto que sustenta este artículo: Teniendo en cuenta que no puede colegirse la responsabilidad fiscal del interventor a partir de la del contratista ¿De qué manera se prueba el dolo o la culpa grave de los interventores en los casos de Responsabilidad Fiscal tramitados ante la Contraloría General de la República -Gerencia Bolívar-, a partir de la Ley 1474 de 2011 ?

El desarrollo investigativo fue en tres momentos distintos, el primero basado en fuente bibliográfica, permitió la descripción de los estándares de valoración probatoria en los procesos de responsabilidad fiscal; en el segundo momento se analizaron los casos de muestra (7 procesos de responsabilidad fiscal que involucraron interventores como presuntos responsables, iniciados por la Contraloría General de la República -Gerencia departamental de Bolívar-, a partir de enero de 2012, y que 
tienen fallos ejecutoriados antes de diciembre de 2018) para identificar las líneas generales de valoración probatoria y finalmente, en el tercer momento se logró reconstruir las diferentes líneas argumentativas de los fallos con responsabilidad fiscal de los interventores.

\section{DeBATE Y DISCUSIÓN}

\section{Elementos de la Responsabilidad Fiscal en Colombia}

Según la página institucional de la Contraloría General de la República los antecedentes de la Responsabilidad Fiscal se remontan a 1923, año en el que el presidente Pedro Nel Ospina promulgó la Ley 42 (1923), que pretendía la organización de la contabilidad del estado y creó el departamento de Contraloría; posteriormente mediante el Decreto 911 (1932) se estableció la obligatoriedad de rendir cuentas por parte de tal departamento.

Posteriormente, a partir de la reforma constitucional de 1945 se establecen los procedimientos y mecanismos que debe tener la institución para realizar el control, los cuales fueron desarrollados más adelante con la Ley 70 (1975), originando los controles: previo, perceptivo y control numérico legal; modificado por la Constitución Política (CP, 1991) al establecer el control posterior, el cual se basa en la eficiencia, la economía, la eficacia y el análisis de los costos ambientales.

En desarrollo de la norma constitucional, la Ley 610 (2000) constituyó una de las grandes reformas de la responsabilidad fiscal, porque rediseña el proceso de responsabilidad fiscal, definiendo conceptos nucleares tales como el concepto de gestión fiscal y los elementos que estructuran la responsabilidad fiscal, norma que ha sido complementada por otras, como por ejemplo la Ley 1474 (2011). 


\section{Noción de responsabilidad Fiscal}

El concepto de responsabilidad jurídica es uno de los más mencionados, usados y recurrentes en el Derecho. Incluso Kelsen (1982) se refirió a la responsabilidad de la persona jurídica como un aspecto distinto a la obligación de la persona jurídica, en tanto esta sería una especie de obligación secundaria producto del incumplimiento de una primera obligación. Existen diferentes tipos de responsabilidad jurídica, según la obligación primaria de la que se deriva, encontrando, por ejemplo: responsabilidad civil, disciplinaria, penal y la que nos ocupa: la responsabilidad fiscal.

La Responsabilidad Fiscal, al igual que la disciplinaria está orientada a revisar la actuación de quienes ejercen funciones públicas, mientras la segunda examina la conducta del servidor de cara a los principios éticos y morales que se le exigen normativamente; la primera, se concentra en el análisis del manejo de los recursos públicos que haga el agente, el análisis de su gestión de tales bienes, a partir de los principios y criterios normativos (González, 2007). Para Ordóñez (2007) la responsabilidad fiscal es la obligación que tiene aquel que gestiona los bienes públicos, de resarcir cualquier detrimento patrimonial causado por su conducta - calificada normativamente como dolosa o gravemente culposa-.

En ese mismo sentido, la Ley 610 (2000), establece que “(...) la responsabilidad fiscal tiene por objeto el resarcimiento de los daños ocasionados al patrimonio público como consecuencia de la conducta dolosa o culposa de quienes realizan la gestión fiscal, mediante el pago de una indemnización pecuniaria" (art. 4). Cabe mencionar que esta Responsabilidad recae sobre quien se identifica como gestor fiscal, es decir que este concepto es básico para comprender la manera cómo, en el caso de estudio, los interventores terminan siendo vinculados a los procesos de responsabilidad fiscal y declarados responsables, al respecto la Ley 610 (2000), enseña que la gestión fiscal es: 
(...) el conjunto de actividades económicas, jurídicas y tecnológicas, que realizan los servidores públicos y las personas de derecho privado que manejen o administren recursos o fondos públicos, tendientes a la adecuada y correcta adquisición, planeación, conservación, administración, custodia, explotación, enajenación, consumo, adjudicación, gasto, inversión y disposición de los bienes públicos, así como a la recaudación, manejo e inversión de sus rentas en orden a cumplir los fines esenciales del Estado, con sujeción a los principios de legalidad, eficiencia, economía, eficacia, equidad, imparcialidad, moralidad, transparencia, publicidad y valoración de los costos ambientales (art. 3).

\section{Elementos de la Responsabilidad Fiscal}

Entendida como una obligación secundaria, la responsabilidad fiscal se origina en el incumplimiento del deber de no dañar, por parte de quienes ejercen la gestión fiscal. Para que nazca, deben presentarse unas condiciones que la doctrina de manera general ha denominado elementos de la responsabilidad: la conducta, el daño, el nexo causal y la culpa o el dolo. Para efectos académicos se puede precisar que los primeros tres elementos son de tipo objetivo y el último de tipo subjetivo.

\section{- Elementos objetivos de la Responsabilidad Fiscal}

La conducta, es de la que se ocupa la responsabilidad fiscal; específicamente la conducta del gestor fiscal. El comportamiento que presuntamente incumple la obligación de no dañar en el manejo del patrimonio público, ejecutada por aquellos que tienen poder de decisión sobre estos recursos. Esta conducta puede ser activa (acción del gestor fiscal) o pasiva (consistente en la omisión). La definición legal de gestión fiscal es bastante amplia. Puede considerarse entonces que las actividades que surgen de la gestión fiscal son múltiples e incluso indeterminables, vinculan diferentes procesos y funcionarios de distintos niveles al interior de la administración e incluso, contratistas independientes a la 
Entidad. Sobre esto, la Corte Constitucional colombiana en Sentencia C-840 (2001), expresó que a la luz de la CP (1991) la gestión fiscal no puede reducirse a enfoques económico-formalistas, en tanto los servidores públicos deben actuar no solo salvaguardando el erario sino, ante todo, estimulando su concreto proyecto de gestión y resultados.

La conducta a la que se refiere la Responsabilidad Fiscal, puede ser una acción u omisión, ineficaz, ineficiente, inoportuna e inequitativa desplegada por el gestor fiscal en cualquier actividad propia de su gestión sobre los bienes y recursos del estado que se encuentran bajo su control y sobre los cuáles tiene poder de decisión, afectando con ello el cumplimiento de los fines del Estado (Sentencia 2093, 2004).

$\mathrm{Al}$ respecto, el Consejo de Estado, estableció que la responsabilidad fiscal ha de versar sobre el manejo de bienes y recursos o fondos públicos, respecto a los cuáles tanto los servidores públicos como los particulares tienen a cargo la custodia $\mathrm{u}$ ostentan un papel decisorio (Sentencia 2013-01024, 2016). La conducta desplegada por quien tiene la calidad de gestor fiscal ha de ocasionar un daño a los bienes públicos, siendo de carácter eminentemente patrimonial y no sancionatoria, la misma es indiferente siempre que no cause detrimento al erario, es decir que, si de la omisión de determinado deber no se infiere un daño en los bienes públicos, no hay lugar a este tipo de responsabilidad, pudiendo por ejemplo existir responsabilidad disciplinaria, civil o penal (Henao, 2007).

En cuanto al segundo elemento, el daño: La Ley 610 (2000), comprende como daño patrimonial al Estado la lesión del patrimonio público, representada en el menoscabo, disminución, perjuicio, detrimento, pérdida, uso indebido o deterioro de los bienes o recursos públicos, o a los intereses patrimoniales del Estado. Es decir el daño en la responsabilidad Fiscal es entendido en sentido objetivo (Sentencia C-340, 2007).

Es claro entonces que el daño al que se refiere la responsabilidad fiscal es uno de tipo estrictamente económico, en sus dos 
modalidades existentes, esto es daño emergente y lucro cesante. De igual forma, la Ley 610 (2000) dispone como requisito para abrir un proceso de responsabilidad fiscal la exigencia de la existencia de un daño, de lo que claramente se infiere que debe ser cierto y pasado, entre otras cosas como consecuencia lógica de un sistema de control fiscal posterior y selectivo.

De esta forma la ley exige que cuando vaya a iniciarse un proceso un proceso de responsabilidad el daño exista, es decir, ya se haya consumado o producido. Creemos que esta disposición es sana puesto que la certeza en el daño futuro es una certeza relativa. Sobre el futuro es imposible tener certeza absoluta puesto que siempre existe un margen de error en las predicciones. Esto podría entonces acarrear injusticias al atribuir responsabilidad fiscal a alguien - tendría que acarrear con las graves consecuencias que ello implica - sobre un daño que finalmente no se produjera. En este caso se presentaría un enriquecimiento sin causa por parte del Estado y el ciudadano podría demandar para que le reembolsaran lo pagado (...) (Concepto 80112 EE15354, 2006, §. 2, 2.5, párr. 8).

(...) De todas formas es conveniente mencionar que en las situaciones en que la Contraloría detecte la posibilidad real de que se presente un daño futuro deberá hacer uso de la facultad de advertencia consagrada en el artículo 5 del Decreto Ley 267 de 2000 (...) (Concepto 80112 EE15354, 2006, §. 2, 2.5, párr. 11).

El tercer y último elemento objetivo de responsabilidad fiscal es el nexo causal, entendido como la conexión entre la conducta activa u omisiva del gestor fiscal y el acaecimiento del daño en los bienes o intereses públicos. Esta conexión puede ser directa (es decir la responsabilidad fiscal surge por el incumplimiento de una obligación propia) o indirecta en condición de delegatoria, vigilante o nominador de aquel quien de manera directa produce la lesión a los bienes e intereses públicos.

Ahora bien, el centro del asunto es, ¿cómo comprender esta conexión? Desde un punto de vista físico de relaciones de causa efecto o son necesarios otros criterios para establecer su existencia. Para 
Amaya (2002), además de acreditar el nexo material de relación causa efecto, es necesario realizar un análisis desde la teoría de la causalidad adecuada, según la cual si bien un hecho puede tener diversas causas, solo una se constituye como la causa eficiente, la que es normalmente idónea para producir este resultado.

Tal como se establece en la teoría general de la responsabilidad civil, el nexo de causalidad se puede romper a través de la prueba del acaecimiento de una de las denominadas causas extrañas; sin embargo por la órbita que ocupa a la responsabilidad fiscal es lógico en primera medida, que se excluye de estas causas, la culpa exclusiva de la víctima, porque en estos procesos la entidad afectada es siempre una persona jurídica de carácter público y segundo, en relación al hecho de un tercero, se exige que el hecho sea tal que desborde las posibilidades de contención del gestor fiscal, caso en el cuál se estaría más bien en los terrenos del caso fortuito o de la fuerza mayor. En conclusión, solo son aceptables dos de las cuatro causas extrañas establecidas para la responsabilidad civil en general: caso fortuito y/o fuerza mayor (Amaya, 2002).

\section{- Elemento subjetivo de la Responsabilidad Fiscal}

La Ley 610 (2000) califica la acción u omisión del gestor fiscal, introduciendo un criterio subjetivo, esto es que se haya cometido con culpa o dolo. La culpa desde la cual es posible pregonar responsabilidad, según la Sentencia C-619 (2002) de la Corte Constitucional colombiana, es la culpa grave, que se entiende desde el Código Civil Colombiano-CCC (Ley 84, 1873, art. 63) como aquella en la que ni siquiera un ser humano descuidado incurriría. Para Mazeaud, Mazeaud, Tunc, Capitant y Alcala (2017) es una imprudencia o error que solo se explica por la temeridad del agente. Es decir, que se trata de una exigencia de diligencia disminuida, en tanto se le pide al gestor fiscal actuar con los mínimos de cuidado que lo haría un hombre descuidado con los negocios ajenos. Por su parte, el 
dolo, entendido desde el mismo artículo 63 es la intención de inferir daño (CCC, 1873).

La culpa puede a su vez ser clasificada como culpa normativa cuando se materializa en la trasgresión u omisión de una norma; culpa imprudente cuando se desatiende el deber general de prudencia; finalmente culpa por impericia cuando consiste en una actuación contraria a aquella pericia que se espera de quien ejerce una profesión u oficio (cuando se trata de una profesión que requiere licencia para su ejercicio, si la persona tiene la licencia surge la presunción de la pericia si actúa sin ella se presume la impericia) (Tamayo, 2007).

En materia de responsabilidad fiscal se responde por los hechos propios o por los de un tercero (CCC, 1873). Las personas son responsables no solo de sus actos; sino también de los de aquellos que estuvieron bajo su cuidado. Este tipo de responsabilidad es la base para que se pueda vincular a la autoridad nominadora. Es decir que quien elige o delega, no pierde en ningún momento la obligación de vigilar, así como también es responsable por escoger a quien no tiene las competencias para desarrollar la tarea asignada. Tratándose del interventor contractual, si bien cumple tareas de vigilancia su responsabilidad se erige a partir de la prueba de la falla de sus obligaciones propias del negocio jurídico (esto es a sus obligaciones y deberes) y no solo porque el contratista haya ocasionado un daño.

Hasta el momento se ha hablado de acreditar probatoriamente el dolo o la culpa grave; sin embargo hay que traer a cuento algunas disposiciones de la Ley 1474 (2011), que en materia contractual establece presunciones de culpa grave respecto de algunas actividades del proceso y además señala que se presume el actuar doloso cuando por los mismos hechos haya sido declarado penal o disciplinariamente responsable; sin embargo esta presunción no significa en forma alguna que exista una posibilidad de responsabilidad objetiva en esos casos sino que corresponde a una carga invertida de la prueba (Ley 1474, 2011, art. 118). 


\section{Prueba de la responsabilidad Fiscal en Colombia}

De manera general existen dos grandes sistemas de estructuración de la responsabilidad jurídica: el primero denominado comúnmente "sistema subjetivo de responsabilidad en el que la característica determinante es la existencia de culpa o dolo en el actor; el segundo llamado sistema objetivo, el elemento central es el daño, de manera que, sea la culpa o el dolo del autor son indiferentes para predicar su responsabilidad" (Fernández, 2014, p. 98). En el primer esquema quien causare un daño imputable a su actuar con culpa o dolo es responsable; mientras que en el segundo el que causare un daño imputable a su actuar debe responder. Cada esquema determina los elementos de la responsabilidad y por lo tanto el debido alcance probatorio de la misma:

La responsabilidad "objetiva", por oposición a la "subjetiva" describe hipótesis de imputabilidad sin culpa, donde la culpabilidad carece de relevancia para estructurarla remitiéndose a factores objetivos como el riesgo o el peligro, la capacidad de asumir los costos de evitación o de reparar la lesión, fundándose en la situación del sujeto respecto de las cosas, su posición o relación con sus congéneres o el ejercicio de una actividad riesgosa o peligrosa permitida por su utilidad social, verbi gratia, la custodia de una cosa, la propiedad sobre ésta, el uso de un animal o el riesgo (Sentencia 2001-01054, 2009).

En un Régimen subjetivo de responsabilidad jurídica se sigue regla probatoria: quien pretenda obtener el resarcimiento de un daño, deberá probarla conducta, el daño, el nexo causal entre daño y conducta y la culpa del autor, lo que se denomina culpa probada. En el esquema probatorio culpa probada es entonces, el más exigente de todos para quien demande el resarcimiento, además deja mayor posibilidad de defensa a quien infrinja el daño, que puede exonerarse atacando la existencia de cualquiera de los elementos. Se afirma que, cuando se trata de culpa probada, la existencia de la culpa se discutirá, a partir, en principio, de la prueba de la debida diligencia y cuidado. 
Flexibilizando el esquema anterior, surge el de la Presunción de Culpa, en la que quien pretende el resarcimiento, solo tendrá que probar hecho, daño y nexo causal, usando la presunción de culpa es su favor; por su parte, quien se repute responsable podrá eximirse atacando la existencia de cualquiera de los elementos probados, o derribándola a partir de la prueba de la debida diligencia y cuidado (esquema de culpa presunta).

La responsabilidad fiscal en Colombia sigue el esquema de culpa probada; sin embargo, existen algunas disposiciones armónicas que flexibilizan un poco el esquema probatorio. Es así como debe añadirse que, en contratación estatal, la Ley 1474 (2011), establece presunciones de culpa grave respecto de algunas actividades del proceso contractual y señala que se presume el actuar doloso cuando por los mismos hechos haya sido declarado penal o disciplinariamente responsable.

En cuanto al aspecto operativo de la labor probatoria, la Ley 610 (2000, cap. I, tít. II) al regular el Proceso de Responsabilidad Fiscal (Actuación Procesal) se ocupa de ello, partiendo como es lógico, en primera medida, por establecer el principio de necesidad de la prueba (art. 22)1 . Lo anterior, complementado por la aclaración contenida en la misma Ley 610 (2000, art. 23), según la cual solo es posible proferir una decisión que declare la responsabilidad fiscal cuando milite prueba que lleve a la certeza del daño patrimonial y la responsabilidad del sujeto investigado (es decir certeza en el fallador de la existencia de todos y cada uno de los elementos que constituyen este tipo de responsabilidad). En relación con los medios de prueba, se deja la puerta abierta a cualquier medio de prueba reconocido por la ley colombiana, debiéndose remitir entonces a los señalados en el Código General del Proceso-CGP (Ley 1564, 2012).

Así las cosas, podrán tenerse como medios de prueba válidos en los casos de responsabilidad fiscal, los dispuestos en el artículo 165 del estatuto general del proceso. Estos, deben ser apreciados de

1 "Necesidad de la prueba. Toda providencia dictada en el proceso de responsabilidad fiscal debe fundarse en pruebas legalmente producidas y allegadas o aportadas al proceso" (Ley 610, 2000, art. 22). 
manera integral, según las reglas de la sana crítica y la persuasión racional. Al respecto Luna (2018) plantea "al hablar de valoración de la prueba, se hace referencia a la labor del juez, dígase que obligatoria, de realizar un análisis sobre el mérito de la convicción de la prueba" (p. 122).

Resta aclarar que si se pretende hacer valer una de las presunciones legalmente establecidas, habrá de ceñirse a lo dispuesto en el CGP (2012, art. 166), de manera que es imperativo la prueba de los hechos en los que se funda la presunción de culpa. La Ley 1474 (2011, art. 118) establece qué deberá probar la Contraloría, en cualquiera de los casos descritos, si pretende hacer uso de la presunción de culpabilidad. La Tabla 1 muestra la presunción de dolo en la conducta del gestor fiscal, los hechos que fundamentan la presunción; la prueba requerida y el hecho presumido; y la Tabla 2 muestra la presunción de culpa, la prueba requerida y el hecho presumido.

TABLA 1.

Presunción de dolo en la conducta del gestor fiscal

\begin{tabular}{|c|c|c|}
\hline $\begin{array}{l}\text { Hechos que fundamentan la } \\
\text { presunción }\end{array}$ & Prueba requerida & $\begin{array}{l}\text { Hecho } \\
\text { presumido }\end{array}$ \\
\hline $\begin{array}{l}\text { La conducta endilgada al } \\
\text { gestor fiscal en el proceso de } \\
\text { Responsabilidad constituye al } \\
\text { mismo tiempo una conducta típica, } \\
\text { antijurídica y culpable, por la cual } \\
\text { ha sido condenado previamente } \\
\text { por la justicia penal colombiana, } \\
\text { estando en firme la condena. }\end{array}$ & $\begin{array}{l}\text { Debe probarse la existencia } \\
\text { de la condena penal por la } \\
\text { comisión de un delito por } \\
\text { la misma conducta que se } \\
\text { investiga en el proceso de } \\
\text { responsabilidad fiscal. } \\
\text { Debe probarse la firmeza de } \\
\text { la condena. }\end{array}$ & $\begin{array}{l}\text { El gestor } \\
\text { fiscal actuó } \\
\text { con dolo, } \\
\text { esto es con } \\
\text { la intención } \\
\text { deliberada } \\
\text { de producir } \\
\text { daño. }\end{array}$ \\
\hline $\begin{array}{l}\text { La conducta endilgada al } \\
\text { gestor fiscal en el proceso de } \\
\text { Responsabilidad constituye } \\
\text { al mismo tiempo una falta } \\
\text { disciplinaria, por la cual ha sido } \\
\text { sancionado previamente por parte } \\
\text { de la autoridad disciplinaria y } \\
\text { dicha sanción se encuentra en } \\
\text { firme. }\end{array}$ & $\begin{array}{l}\text { Deberá probarse la existencia } \\
\text { de la sanción disciplinaria } \\
\text { al gestor fiscal como } \\
\text { consecuencia de un proceso } \\
\text { adelantado por esta conducta. } \\
\text { Deberá probarse la firmeza } \\
\text { del acto administrativo } \\
\text { contentivo del fallo de } \\
\text { responsabilidad disciplinaria. }\end{array}$ & $\begin{array}{l}\text { El gestor } \\
\text { fiscal actuó } \\
\text { con dolo, } \\
\text { esto es con } \\
\text { la intención } \\
\text { deliberada } \\
\text { de producir } \\
\text { daño. }\end{array}$ \\
\hline
\end{tabular}

Fuente: Elaboración propia con información adaptada de lo ordenado en el código general del proceso, la Ley 610 (2000), Ley 1474 (2011) y otras disposiciones. 
TABLA 2.

Presunción de culpa

\begin{tabular}{|c|c|c|}
\hline $\begin{array}{l}\text { Hechos que fundamentan } \\
\text { la presunción }\end{array}$ & Prueba requerida & Hecho presumido \\
\hline $\begin{array}{l}\text { El gestor fiscal elaboró } \\
\text { pliegos de condiciones o } \\
\text { términos de referencia } \\
\text { incompletos, ocasionando } \\
\text { una interpretación o } \\
\text { decisión técnica que afectó } \\
\text { el patrimonio de la Entidad. }\end{array}$ & $\begin{array}{l}\text { La participación del gestor } \\
\text { fiscal en la construcción } \\
\text { de los términos de la } \\
\text { referencia o su deber } \\
\text { funcional de hacerlo. } \\
\text { La incompletitud de los } \\
\text { términos de referencia. } \\
\text { La lesividad de la } \\
\text { interpretación o decisión } \\
\text { técnica } \\
\text { La relación entre el } \\
\text { defecto de los términos y } \\
\text { la decisión o interpretación } \\
\text { técnica lesiva. }\end{array}$ & $\begin{array}{l}\text { El Gestor Fiscal actuó } \\
\text { con culpa grave, es } \\
\text { decir sin la prudencia } \\
\text { o preocupación } \\
\text { mínima exigible a una } \\
\text { persona descuidada. }\end{array}$ \\
\hline $\begin{array}{l}\text { El gestor fiscal elaboró } \\
\text { pliegos de condiciones o } \\
\text { términos de referencia } \\
\text { confusos o ambiguos, } \\
\text { ocasionando una } \\
\text { interpretación o decisión } \\
\text { técnica que afectó el } \\
\text { patrimonio de la Entidad. }\end{array}$ & $\begin{array}{l}\text { La participación del gestor } \\
\text { fiscal en la construcción } \\
\text { de los términos de la } \\
\text { referencia o su deber } \\
\text { funcional de hacerlo. } \\
\text { La inexactitud o } \\
\text { ambigüedad de los } \\
\text { términos de referencia. } \\
\text { La lesividad de la } \\
\text { interpretación o decisión } \\
\text { técnica². } \\
\text { La relación entre el } \\
\text { defecto de los términos y } \\
\text { la decisión o interpretación } \\
\text { técnica lesiva. }\end{array}$ & $\begin{array}{l}\text { El Gestor Fiscal actuó } \\
\text { con culpa grave, es } \\
\text { decir sin la prudencia } \\
\text { o preocupación } \\
\text { mínima exigible a una } \\
\text { persona descuidada. }\end{array}$ \\
\hline
\end{tabular}

2 Es de aclarar que en Sentencia C-512 (2013), la Corte Constitucional colombiana analizó las presunciones de culpa grave y dolo contenidas en la Ley 1474 (2011), encontrando que no contravienen la lógica; al revés, en todos los casos enunciados hay aspectos objetivos y verificables, que son situaciones relevantes, a las que la presunción da firmeza, para cuidar bienes jurídicos importantes como son la contratación pública, la adecuada revisión de la ejecución de los contratos estatales, asegurar los bienes públicos, y garantizar el pago de salarios y emolumentos laborales. 


\begin{tabular}{|c|c|c|}
\hline $\begin{array}{l}\text { Hechos que fundamentan } \\
\text { la presunción }\end{array}$ & Prueba requerida & Hecho presumido \\
\hline $\begin{array}{l}\text { El gestor fiscal incumplió } \\
\text { las obligaciones del contrato } \\
\text { de interventoría o las } \\
\text { funciones de supervisión } \\
\text { afectando la correcta } \\
\text { ejecución de los contratos, o } \\
\text { las condiciones de calidad y } \\
\text { oportunidad ofrecidas por el } \\
\text { contratista. }\end{array}$ & $\begin{array}{l}\text { La calidad de supervisor o } \\
\text { interventor. } \\
\text { La falta a los deberes } \\
\text { legales y contractuales de } \\
\text { quienes son interventores } \\
\text { o supervisores. } \\
\text { La afectación al } \\
\text { cumplimiento del contrato. }\end{array}$ & $\begin{array}{l}\text { EL interventor o } \\
\text { supervisor actuó con } \\
\text { culpa grave, es decir } \\
\text { sin la prudencia o } \\
\text { preocupación mínima } \\
\text { exigible a una persona } \\
\text { descuidada. }\end{array}$ \\
\hline $\begin{array}{l}\text { Sobrecostos en productos y } \\
\text { servicios, como consecuencia } \\
\text { de la falta de comparación } \\
\text { con las condiciones del } \\
\text { mercado o con otras } \\
\text { propuestas recibidas. }\end{array}$ & $\begin{array}{l}\text { El sobrecosto en relación } \\
\text { con las condiciones del } \\
\text { mercado o con las otras } \\
\text { ofertas recibidas. }\end{array}$ & $\begin{array}{l}\text { EL funcionario actuó } \\
\text { con culpa grave, es } \\
\text { decir sin la prudencia } \\
\text { o preocupación } \\
\text { mínima exigible a una } \\
\text { persona descuidada. }\end{array}$ \\
\hline $\begin{array}{l}\text { Ocurrido un siniestro } \\
\text { que afecta los bienes de } \\
\text { la Entidad estos no se } \\
\text { encuentran asegurados a } \\
\text { través de una póliza. }\end{array}$ & $\begin{array}{l}\text { Inexistencia de la póliza } \\
\text { que asegure los bienes de } \\
\text { la Entidad. }\end{array}$ & $\begin{array}{l}\text { El funcionario actuó } \\
\text { con culpa grave, es } \\
\text { decir sin la prudencia } \\
\text { o preocupación } \\
\text { mínima exigible a una } \\
\text { persona descuidada. }\end{array}$ \\
\hline $\begin{array}{l}\text { Una vez ocurrido } \\
\text { un siniestro o el } \\
\text { incumplimiento de un } \\
\text { contrato amparado con } \\
\text { póliza, el gestor fiscal no } \\
\text { ejerció la garantía dentro } \\
\text { del término previsto. }\end{array}$ & $\begin{array}{l}\text { Existencia de la póliza } \\
\text { de seguro que ampara } \\
\text { el riesgo y vigencia de la } \\
\text { misma. } \\
\text { Aseveración de constar en } \\
\text { archivo la solicitud a la } \\
\text { compañía aseguradora. }\end{array}$ & $\begin{array}{l}\text { El funcionario } \\
\text { encargado actuó con } \\
\text { culpa grave, es decir } \\
\text { sin la prudencia o } \\
\text { preocupación mínima } \\
\text { exigible a una persona } \\
\text { descuidada. }\end{array}$ \\
\hline $\begin{array}{l}\text { El funcionario ha efectuado } \\
\text { el reconocimiento de } \\
\text { salarios o prestaciones } \\
\text { sociales a determinada } \\
\text { personas o personas que } \\
\text { no cumplen los requisitos } \\
\text { legales o infringiendo la } \\
\text { normativa de la función } \\
\text { pública o las relaciones } \\
\text { laborales. }\end{array}$ & $\begin{array}{l}\text { Existencia de Acto } \\
\text { Administrativo en firme } \\
\text { que reconoce salarios, } \\
\text { prestaciones sociales o } \\
\text { emolumentos laborales a } \\
\text { determinada persona. } \\
\text { Contrariedad entre los } \\
\text { fundamentos fácticos y } \\
\text { normativos del Acto de } \\
\text { reconocimiento y la ley } \\
\text { colombiana. }\end{array}$ & $\begin{array}{l}\text { El funcionario } \\
\text { encargado actuó con } \\
\text { culpa grave, es decir } \\
\text { sin la prudencia o } \\
\text { preocupación mínima } \\
\text { exigible a una persona } \\
\text { descuidada. }\end{array}$ \\
\hline
\end{tabular}

Fuente: Elaboración propia con información adaptada de lo dispuesto en la Ley 1474 (2011). 
El régimen de responsabilidad fiscal es uno subjetivo, en el cual deberá probarse la culpa grave o dolo del gestor fiscal, ya sea a través de cualesquiera de los medios probatorios consagrados y permitidos en nuestro ordenamiento jurídico, o en excepciones legales la prueba de la culpa o el dolo está flexibilizado por un esquema de presunción de culpa, que no elimina la actividad probatoria de la Contraloría, dado que para poder esgrimir la culpa deberán probarse los fundamentos que permiten el nacimiento de la presunción, en favor del ente sancionador. No basta que el funcionario manifieste que hubo un sobrecosto basándose en su mera especulación, es necesario que en el proceso se establezca el comparativo con las condiciones del mercado o con otras ofertas, resultando de ello la determinación del excedente de precio del bien o servicio.

Tratándose del régimen de responsabilidad de interventores, la antes citada Ley 610 (2000, art. 118) crea una presunción de culpa aplicable a aquellos casos en los que el gestor fiscal omite las obligaciones propias de su función afectando la ejecución de los contratos, caso en el cuál no se trata de eximir de prueba a las contralorías, sino de flexibilizar la labor probatoria, generando en el sujeto la necesidad de probar en contra de la presunción.

\section{Principio de Responsabilidad en la Contratación y sus implicaciones en los contratos de Interventoría}

El principio de responsabilidad es de carácter constitucional y tiene asidero en la CP (1991, art. 6; art. 90; art. 124). El artículo 6 que dispone: "los particulares sólo son responsables ante las autoridades por infringir la Constitución, y las leyes. Los servidores públicos lo son por la misma causa y por omisión o extralimitación en sus funciones" (CP, 1991, art. 6). De aquí fácilmente se infiere que el grado de responsabilidad de los funcionarios públicos es mayor en relación con los particulares: los primeros responden por infracciones al ordenamiento jurídico, incumplimiento de las cargas que le han sido asignadas por la misma ley o por actuar por fuera de la órbita de sus competencias o con extralimitación de los poderes concedidos; mientras que los segundos solo por las infracciones al orden jurídico. 
Por su parte, el artículo 90 constitucional tiende el puente entre los funcionarios públicos, los particulares, estableciendo el lazo de responsabilidad entre el Estado y los asociados a partir del daño sufrido por estos, como consecuencia del actuar de los servidores del Estado (CP, 1991, art. 90). Finalmente, el artículo 124 establece que la ley fijará la responsabilidad de los servidores y la forma como esta se hace efectiva, a partir del cual se fundamenta la existencia de los diferentes sistemas de responsabilidad jurídica de los funcionarios públicos, incluyendo el sistema de responsabilidad fiscal (CP, 1991, art. 124$)^{3}$.

\section{Principio de Responsabilidad en la Contratación Estatal. Caso específico de los interventores}

Ahora bien, el principio de responsabilidad en la Contratación estatal viene establecido en la Ley 80 (1993, art. 26), en virtud del cual se establece la obligación a servidores públicos de, en pro del cumplimiento de los fines de la contratación estatal, vigilar el objeto contratado y cuidar los intereses de la Administración, contratista y terceros que puedan verse afectados con su ejecución. Consecuentemente, los servidores públicos responderán por las actuaciones y omisiones antijurídicas y tendrán que indemnizar los daños que ocasionen en virtud de ella (Jaramillo, 2018).

En consonancia con el principio de transparencia fijado en el artículo 24 de esta misma norma, el principio de responsabilidad se ha ido extendiendo en espectro en dos direcciones básicas: la primera en cuanto al sujeto que se vincula, que incluye a los particulares y segundo, en cuanto al tipo de responsabilidad que se les puede

3 Constitucionalmente el principio de la responsabilidad está definido a partir de la CP (1991, art. 6) cuando de forma clara, respecto de las autoridades públicas, señala que son responsables por violar la Constitución y la ley y "por omisión o extralimitación en el ejercicio de sus funciones". Este artículo se relaciona directamente con el artículo 124, que le pasa al legislador la obligación de establecer el régimen de responsabilidad de los servidores públicos y la forma de hacerla efectiva... igualmente, la responsabilidad fiscal de la que habla la Ley 42 (1923), cuando en el cumplimiento de sus deberes el servidor público, por su acción u omisión hubiere causado detrimento patrimonial al Estado (Santofimio, 2007). 
atribuir, que inició siendo solo civil y penal, siendo que hoy, a partir de la Ley 1474 (2011) es responsabilidad fiscal y disciplinaria también (Jaramillo, 2018).

Otra forma de extensión del principio de responsabilidad ha sido la consagración de la solidaridad en la obligación, existente para interventores y supervisores, cuando se cause un daño atribuible a la ejecución o falta de ejecución del contrato. Este principio permite que tanto interventor como supervisores contractuales concurran al pago de las indemnizaciones por tales daños, en el mismo monto y condición que el contratista.

La solidaridad antes que un principio en materia de obligaciones, es más bien una forma en la que se presenta la obligación, encuentra fundamento normativo en el CCC (1873, art. 1568); este tipo de obligación se refiere específicamente a pluralidad en uno de los extremos cuando ésta es divisible, así hay solidaridad activa cuando existen varios acreedores y un deudor que, cumpliendo la obligación en relación con uno de los acreedores cumple en totalidad (CCC, 1873, art. 1570); mientras que existe pluralidad pasiva cuando son varios deudores y el acreedor puede exigir a cualquiera de ellos, el cumplimiento íntegro de la misma (CCC, 1873, art. 1571).

De manera general, cuando las obligaciones son divisibles no opera la solidaridad; sino por el contrario la división de la obligación; no obstante, el mismo CCC (1873, art. 1568) dispone que puede haber solidaridad cuando así se pacte. Es en materia mercantil donde la solidaridad se ha establecido como principio, en consecuencia, las obligaciones mercantiles se entienden solidarias salvo pacto en contrario. En materia de contratación estatal, por integración ha de seguirse la norma civil, es decir que la solidaridad entra no como principio sino como característica de una obligación que ha sido consagrada así en la norma.

En el caso de estudio, la Ley 80 (1993), modificada por la Ley 1474 (2011) y por la Ley 1882 (2018), consagra una obligación solidaria pasiva entre el interventor y supervisor y el contratista, por los daños producto de la celebración, ejecución e incluso liquidación del contrato estatal. 
Sobre esto la Corte Constitucional en la Sentencia C-338 (2014), ha manifestado:

iii) En aquellos eventos en que haya sido posible imputar - con base en culpa grave o dolo- responsabilidad fiscal a más de un sujeto, estos, por determinación directa del artículo 119 de la ley 1474 de 2011, responderán solidariamente (párr. 158).

En tal virtud, la solidaridad que fija el Estatuto Anticorrupción (Ley 1474, 2011, art. 119), entre los encargados de pagar las obligaciones derivadas de un proceso fiscal, no implica la constucción de un parámetro diferente de imputación al señalado en los artículos mentados de la Ley 610 (2000), ni al consagrado en el artículo 118 (Ley 1474, 2011) de aquel grupo de normas, ni a los que la jurisprudencia ha remitido de los preceptos constitucionales aplicables. La razón de la imputación continúa siendo la culpa grave o el dolo del sujeto pasivo del proceso fiscal. Lo que sí es posible es edificar la presunción de culpa, tal como viene establecida en el literal c del artículo 118 (Ley 1474, 2011) antes mencionado.

La solidaridad sólo tiene lugar ante la existencia de un supuesto jurídico: que se sea responsable en materia fiscal. Una vez esto ha sido establecido, lo que la naturaleza solidaria de la obligación permite es el cobro del total de los perjuicios causados a cualquiera de los deudores que, con base en su actuar doloso o gravemente culposo, hayan sido encontrados responsables.

\section{Naturaleza del contrato de interventoría- Obligaciones y cargas}

Establecido lo anterior, es claro entonces que si bien la obligación que surge entre el interventor y el contratista o el funcionario es de tipo solidario los criterios de imputabilidad de cada uno son independientes a los demás, en consecuencia con el objetivo de fijar la responsabilidad de los interventores los funcionarios de las Contralorías habrán de analizar de manera integral las normas que regulan este tipo de contratos y los términos contractuales propios (tanto del contrato de interventoría como del de obra), a fin de tener 
claridad sobre el alcance, objeto contractual y obligaciones a partir de las cuales será posible hacer el juicio de responsabilidad.

El contrato de interventoría es consecuencia también de la aplicación del principio de responsabilidad en materia de contratación estatal, puede ser visto como una herramienta de control y seguimiento de los fines del Estado, vía compra pública. En tal sentido, puede afirmarse que el contrato de interventoría es aquel que se celebra con una persona natural o jurídica para que ejerza el control $\mathrm{y}$ vigilancia de un proyecto y asegure que este se cumpla de acuerdo a los planos, especificaciones, costos y plazos establecidos (Sánchez, 2018).

La Ley 80 (1993, art. 32) cataloga la interventoría dentro de los contratos de consultoría; sin embargo no lo define, al respecto el Consejo de Estado expresa:

Con fundamento los artículos 28 y 29 del Código Civil, la Sala aprecia el criterio de interpretación gramatical, de conformidad con el cual se consulta el diccionario de la Real Academia de la Lengua, donde aparece como segunda acepción de "interventor", la de "persona que autoriza y fiscaliza ciertas operaciones para asegurar su corrección". Desde la perspectiva legal, a la cual también remiten los artículos referidos, se tiene que el artículo 32 de la Ley 80 de 1993 en el numeral 1, al tratar el contrato de obra hace referencia a la interventoría pero no la define, como tampoco lo hace ese artículo en su numeral 2 , incisos 2 y 3 , cuando se refiere la interventoría como una modalidad de consultoría, ni el artículo 53 del mismo estatuto, en el cual se prescribe respecto de la responsabilidad de los interventores. No obstante, una norma jurídica, y a la vez técnica, de la mayor importancia para efectos del caso concreto, el Decreto 2090 de 1989 "por el cual se aprueba el reglamento de honorarios para los trabajos de arquitectura", en el numeral 6 indica que "se entiende por interventoría el servicio prestado por un profesional o persona jurídica especializada, para el control de la ejecución del proyecto arquitectónico o de la construcción". Por último, la jurisprudencia de la Sección Primera del Consejo de Estado ha afirmado que el contrato de interventoría "tiene por objeto supervisar o vigilar que la obra se construya de conformidad con lo estipulado en el contrato (Sentencia 2000-00732, 2013). 
Teniendo como base lo inmediatamente expuesto las actividades propias de la naturaleza del contrato de interventoría son las relacionadas con el control, supervisión, vigilancia y fiscalización de la obra. Todas estas pueden darse desde el punto de vista técnico ${ }^{4}$, administrativo, contable, jurídico o integral, según sea definido en el contrato. Además, entre el contrato de interventoría y el contrato de obra existe la denominada coligación negocial, consistente en la interdependencia que existe entre el contrato de interventoría y el contrato de obra del cual depende:

El Consejo de Estado (Sección $3^{\mathrm{a}}$ ) ha definido la interventoría como un contrato profundamente relacionado en su objeto con el de obra respecto del cual ejerce su labor, y como un contrato que a pesar de ello, es independiente en temas concretos como la prórroga, por ejemplo, o sea, que si la obra se prorroga no significa que pase lo mismo con el del interventor y que el incumplimiento del contrato de obra jamás significa por sí solo el incumplimiento del de interventoría (Sentencia 2000-00732, 2013).

Las negrillas en el texto fortalecen el argumento planteado al inicio de este aparte: si bien contrato de obra e interventoría son coligados, la inejecución del contrato de obra y la consecuente responsabilidad del contratista; no indica de manera inmediata el incumplimiento de las obligaciones del interventor ni mucho menos responsabilidad jurídica de algún tipo. De otro lado, esta interdependencia justifica que la Ley 1474 (2011, art. 85), en relación con la continuidad de la interventoría, disponga que estos podrán prorrogarse por el mismo plazo que se haya ampliado el contrato objeto de la vigilancia.

Ahora bien, la Ley 1474 (2011, art. 84), se ocupa de las facultades y deberes de los interventores, disponiendo que para cumplir con el seguimiento de la obligación contratada por la Entidad a cargo del contratista, los interventores tienen unas facultades y unos deberes específicos a saber:

4 La Interventoría Técnica tiene por objeto controlar y verificar que la ejecución del objeto contractual se haga según las especificaciones señaladas en el Pliego de Condiciones y en la propuesta ganadora (Concepto de la Oficina Jurídica No. 2017EE0038579, 2017). 
TABLA 3.

Facultades y deberes de los interventores

\begin{tabular}{ll}
\hline \multicolumn{1}{c}{\begin{tabular}{c}
\multicolumn{1}{c}{ Facultades de los } \\
interventores
\end{tabular}} & \multicolumn{1}{c}{$\begin{array}{c}\text { Deberes de los } \\
\text { interventores }\end{array}$} \\
\hline $\begin{array}{l}\text { Solicitar informes sobre la ejecución } \\
\text { contractual. }\end{array}$ & $\begin{array}{l}\text { Tener enterada a la entidad sobre } \\
\text { hechos que puedan tipificar actos de } \\
\text { corrupción o conductas punibles. }\end{array}$ \\
$\begin{array}{l}\text { Solicitar aclaraciones sobre la } \\
\text { ejecución contractual. }\end{array}$ & $\begin{array}{l}\text { Mantener informada a la entidad de } \\
\text { actos o hechos que puedan poner en } \\
\text { peligro la ejecución contractual. }\end{array}$ \\
$\begin{array}{l}\text { Solicitar explicaciones sobre la } \\
\text { ejecución contractual. }\end{array}$ & $\begin{array}{l}\text { Mantener informada a la entidad en } \\
\text { caso de presentarse incumplimiento. }\end{array}$ \\
$\begin{array}{l}\text { Conminar al contratista a cumplir } \\
\text { con la obligación pactada en el } \\
\text { término previsto. }\end{array}$ & $\begin{array}{l}\text { Exigir el cumplimiento en la calidad de } \\
\text { los bienes y servicios contratados. }\end{array}$ \\
$\begin{array}{l}\text { Conminar al contratista a cumplir } \\
\text { con la calidad de los bienes y } \\
\text { servicios contratados. }\end{array}$ & $\begin{array}{l}\text { No acreditar como recibida a } \\
\text { satisfacción obra que no ha sido } \\
\text { ejecutada a cabalidad. }\end{array}$ \\
\hline
\end{tabular}

Fuente: Elaboración propia con información adaptada de lo dispuesto en Ley 1474 (2011).

Puede afirmarse que las funciones y obligaciones de los interventores cubren la etapa precontractual, contractual y poscontractual. Incluso, Sánchez (2018) expresa que la interventoría es una actividad proactiva que se vuelve el primer filtro para los entregables del contratista, está llamado a evidenciar el cumplimiento de lo pactado e incluso objetar las entregas en caso que estás no sean acordes con lo pactado.

Análisis de casos de Responsabilidad Fiscal del Interventor

\section{Descripción general de la muestra}

Para hacer el análisis previsto se pidió a la Contraloría General de la República -Gerencia Bolívar-, los fallos con responsabilidad fiscal de los procesos iniciados y fallados en el periodo comprendido 
2012-2018, en los que se vinculara como presunto responsable fiscal a interventores contractuales. Teniendo en cuenta que se requería que los procesos fueran iniciados después a la entrada en vigencia de la Ley 1474 (2011) y que alcanzaran fallo antes de finalizado el segundo semestre de 2018 (con fallo ejecutoriado), la muestra obtenida fue relativamente pequeña, correspondiente a un total de 22 fallos entregados por la Contraloría General-Gerencia Bolívar-.

Sin embargo, hecho un análisis preliminar se encontraron solo 7 casos $^{5}$ con decisión con responsabilidad fiscal en los que se vinculaba a interventores al menos al iniciar el proceso; los restantes fueron descartados ya que tanto la Entidad contratante como los auditores de la Contraloría General anunciaban como interventores a funcionarios de la entidad afectada, que en realidad se desempeñaban como supervisores, excediendo el campo de estudio del proyecto de investigación que ha dado origen a este artículo.

El rango de valor del detrimento patrimonial es amplio, desde los seis millones de pesos a los trescientos sesenta millones de pesos, en todos los procesos, se vinculó de manera solidaria también a supervisores y autoridad nominadora. Otra particularidad de los procesos analizados es que seis de los casos correspondían con una hipótesis de Convenio interadministrativo en los que se había entregado el $100 \%$ del valor del contrato como anticipo. En uno de ellos, aunque también se trataba de Contrato interadministrativo se habían hecho 3 pagos sucesivos hasta constituir el 100\% antes de la suspensión del contrato que nunca se reanudó.

5 De los siete casos de estudio, dos correspondían a Cartagena, los cinco restantes a municipios de Bolívar. Se observa como dato curioso que los correspondientes al municipio de Bolívar estaban en su mayoría (4) relacionados con obras de mitigación de la ola invernal mientras que los del Distrito son relativos a intervenciones viales en distintos tramos de la ciudad. 
Cuatro de los casos estudiados se clasificaron como procesos verbales de responsabilidad fiscal y tres como procesos ordinarios. En los siete casos de estudio, se declaró la responsabilidad fiscal del contratista, mientras que en tres casos se falló también en contra del nominador y en 2 del supervisor. Finalmente cuatro de los casos fueron fallados con responsabilidad del interventor.

\section{Casos de Responsabilidad Fiscal del Interventor}

En primera medida se analizará lo sucedido en los tres fallos en los que no se declaró al interventor responsable fiscal: coinciden en que durante el proceso logró demostrar que había cumplido a cabalidad su función, partiendo sobretodo del hecho de lo poco que había que hacer cuando se habia entregado el $100 \%$ del valor del contrato como anticipo, permitido por la Ley a través de la figura del Convenio interadministrativo. Se evidenciaron los llamados realizados al contratista para el cumplimiento y el informe a la Entidad sobre la suspensión de la obra, su falta de ejecución o indebida ejecución de la misma.

En uno de los casos, la Contraloría General -Gerencia Bolívaraclara que la entrega del anticipo del 100\% luego de la celebración del convenio interadministrativo, en sí misma, no puede constituirse en un indicio de culpa o dolo, en tanto se trata de una conducta permitida por el sistema de contratación colombiano. Sin embargo, en estos casos, la labor de interventoría, se encuentra atada de manos debido a la entrega del valor total del contrato como anticipo, si bien en dos casos se trataba de suspensión de puntos de obras por el efecto del invierno, una vez pasada la ola invernal no se había constatado actuación por parte del contratista a pesar del pago total de la obra. En uno de los casos incluso, la Entidad había hecho uso de la cláusula exorbitantes, presentándose un debate legal accesorio sobre tal situación.

A continuación se presenta un cuadro esquemático que contiene los elementos analizados en los cuatro procesos en los que se consideró responsable fiscal al interventor: 
TABLA 4.

Cuadro esquemático de los casos donde se declara responsable fiscal al interventor

\begin{tabular}{|c|c|c|c|c|c|}
\hline $\begin{array}{l}\text { Tipo de } \\
\text { Proceso }\end{array}$ & $\begin{array}{l}\text { Elemento } \\
\text { Subjetivo }\end{array}$ & $\begin{array}{l}\text { Tipo de } \\
\text { Conducta }\end{array}$ & Conducta Desplegada & Presunción & Prueba \\
\hline $\begin{array}{l}\text { Prf } \\
\text { ordinario }\end{array}$ & $\begin{array}{l}\text { Culpa } \\
\text { grave }\end{array}$ & Omisión & $\begin{array}{l}\text { Conducta pasiva del } \\
\text { interventor, falta de } \\
\text { ejercicio de sus facultades } \\
\text { e incumplimiento de los } \\
\text { deberes. A pesar de haber sido } \\
\text { contratada la interventoría } \\
\text { integral nunca medió una } \\
\text { intervención administrativa o } \\
\text { financiera, o una solicitud de } \\
\text { informes. }\end{array}$ & $\begin{array}{l}\mathrm{Si} \text {, aunque no se manifieste } \\
\text { expresamente es clara su } \\
\text { aplicación. El interventor no } \\
\text { logra derribar la presunción. }\end{array}$ & $\begin{array}{l}\text { Falta de elementos en la Entidad que } \\
\text { demostraran documentalmente el ejercicio de } \\
\text { la interventoría. } \\
\text { No había evidencia del informe de suspensión } \\
\text { de obra. } \\
\text { Existencia de Actas de recibo a satisfacción. } \\
\text { No había evidencia de reunión entre } \\
\text { interventor y contratista. } \\
\text { En versión libre el interventor afirma que los } \\
\text { documentos sobre su gestión deberían estar } \\
\text { en la Entidad, que no tiene copia en su poder. }\end{array}$ \\
\hline $\begin{array}{l}\text { Prf } \\
\text { verbal }\end{array}$ & $\begin{array}{l}\text { Culpa } \\
\text { grave }\end{array}$ & Omisión & $\begin{array}{l}\text { Incumplimiento de los deberes } \\
\text { del interventor }\end{array}$ & $\begin{array}{l}\mathrm{Si} \text {, aunque no se manifieste } \\
\text { expresamente es clara su } \\
\text { aplicación. El interventor no } \\
\text { logra derribar la presunción. }\end{array}$ & $\begin{array}{l}\text { Existía un Acta de recibido de conformidad } \\
\text { cuando la obra no cumplía las características } \\
\text { contratadas. } \\
\text { No había evidencia documental de informe } \\
\text { alguna sobre la suspensión de la obra. } \\
\text { El interventor asegura existen pruebas de su } \\
\text { gestión, pero no las allega. }\end{array}$ \\
\hline $\begin{array}{l}\text { Prf } \\
\text { ordinario }\end{array}$ & $\begin{array}{l}\text { Culpa } \\
\text { grave }\end{array}$ & Omisión & $\begin{array}{l}\text { Falta de ejercicio de las } \\
\text { facultades legales. Interventor } \\
\text { poco activo. }\end{array}$ & $\begin{array}{l}\mathrm{Si} \text {, aunque no se manifieste } \\
\text { expresamente es clara su } \\
\text { aplicación. El interventor no } \\
\text { logra derribar la presunción. }\end{array}$ & $\begin{array}{l}\text { No existía prueba alguna de la gestión del } \\
\text { interventor, conminando al cumplimiento del } \\
\text { contrato. } \\
\text { Los informes de interventoría no reportaban } \\
\text { el incumplimiento del contrato. }\end{array}$ \\
\hline $\begin{array}{l}\text { Prf } \\
\text { verbal }\end{array}$ & $\begin{array}{l}\text { Culpa } \\
\text { grave }\end{array}$ & Omisión & $\begin{array}{l}\text { Conducta pasiva del } \\
\text { interventor, falta de } \\
\text { ejercicio de sus facultades e } \\
\text { incumplimiento de los deberes. }\end{array}$ & $\begin{array}{l}\mathrm{Si} \text {, aunque no se manifieste } \\
\text { expresamente es clara su } \\
\text { aplicación. El interventor no } \\
\text { logra derribar la presunción. }\end{array}$ & $\begin{array}{l}\text { No existían solicitudes de cumplimiento al } \\
\text { contratista por parte del interventor. } \\
\text { No hay informe notificando el incumplimiento } \\
\text { a la entidad. }\end{array}$ \\
\hline
\end{tabular}

Muestra de los fallos de la Contraloría General de la República -Gerencia Bolívar- (2012-2018) donde se declara responsable fiscal al interventor.

Fuente: Elaboración propia con información acopiada de los fallos. 
El juicio de responsabilidad, de manera general, recae sobre la inactividad del interventor; en tanto de todos se denuncia su omisión, entrando en el campo de la culpa normativa (infracción del ordenamiento jurídico), ya sea porque no ejercieron las facultades otorgadas (que envuelven un deber correlativo) o porque de manera directa incumplieron un deber. La prueba, a partir de la cual se construyó el juicio fue en la realidad la ausencia de evidencia de la actuación del interventor, a partir de la cual se afirmó su omisión.

Debido a que la Ley 80 (1993) establece que todas las órdenes del interventor deberán constar por escrito, la prueba documental tiene un gran valor en la apreciación que hace la Contraloría sobre los hechos del caso. Por su parte, teniendo en cuenta que había operado la presunción de la Ley 1474 (2011, art. 118, lit. c), no bastaba la simple afirmación del interventor acerca de su buena gestión; sino que estaba obligado a derrumbar la presunción de culpa, aportando prueba del cumplimiento de sus deberes y obligaciones contractuales.

\section{Conclusiones}

En todos los casos de fallo con responsabilidad fiscal contra el interventor, se encuentra que el actuar de la Contraloría General -Gerencia Bolívar-, se ajustó a lo que se ha establecido como hipótesis de este texto: consideró las responsabilidades de contratistas e interventores como independientes, se concentró en el análisis de la conducta del interventor a la luz de las normas y de los contratos (de interventoría y obra), dio prevalencia a la prueba documental y fundamentó la existencia o no de la culpa grave en cada caso.

Mientras reconocía la solidaridad de la obligación (aunque sin declararlo expresamente en la parte resolutiva) la Contraloría General de la República -Gerencia Bolívar-, comprendía la necesidad de demostrar en relación con los interventores la existencia de cada uno de los elementos que estructuran la responsabilidad fiscal, incluyendo la culpa grave o el dolo (aunque se apoyó completamente en la presunción de la Ley 1474, 2011, art. 118, lit. c) 
De igual forma se observa que, las facultades concedidas de manera especial a los interventores implican el deber correlativo de ejercerlas, en tal sentido es necesario que con miras a derribar la presunción de culpa grave producto del incumplimiento de la actividad de interventoría, se logre probar documentalmente el ejercicio de tales facultades de manera oportuna. Se reitera, la importancia de la prueba documental en tratándose de derribar la presunción de responsabilidad, teniendo en cuenta que en los casos en los que se fallo sin responsabilidad del interventor la prueba conducente al fallo, fue precisamente la evidencia escrita del ejercicio de la vigilancia y el control por parte del interventor.

Esto se compadece con el hecho de que la actividad contractual es eminentemente reglada y la ejecución de las actividades $u$ obligaciones pactadas, sobre todo en contratos de obra, impone la carga de llevar un registro pormenorizado de las recomendaciones o requerimientos que se hagan por parte de la interventoría cada vez que se presente una situación especial. Es decir, no es cuestionable en principio la necesidad de adoptar medidas de corrección que puedan conllevar, incluso, a la modificación en los plazos o valores contratados; lo que realmente puede derivar en un reproche con incidencia fiscal es que el interventor no cumpla con su rol de manera activa, además de la elaboración de un registro, que permita al operador fiscal conocer la verdadera historia de la ejecución del contrato estatal.

Como observación de cierre se debe resaltar que cada caso en estudio requería un análisis pormenorizado tanto del contrato de interventoría como del contrato de obra, a fin de establecer la posible responsabilidad. La interdependencia de ambos, determina la expectativa que se tiene en relación con el interventor y por lo tanto conduce el juicio que pueda hacer la contraloría al momento de fallar, razón por la cual sería interesante seleccionar muestras mayores, al menos de las gerencias de los diez departamentos más grandes del país, a fin de establecer si esta tendencia es generalizada en la Contraloría General de la República. 


\section{REFERENCIAS}

Amaya, U. (2002). Teoría de la Responsabilidad Fiscal. Aspectos Sustanciales y procesales. Bogotá, D.C.: Universidad Externado de Colombia.

Fernández, A. (2014). El concepto de responsabilidad. En, J. D. Sánchez, Homenaje a José Barroso Figueroa (pp. 95-110). México, D. F.: Universidad Autónoma de México.

González, E. (2007). El control Fiscal y la Responsabilidad Fiscal en Colombia. Bogotá, D.C.: Doctrina y Ley.

Henao, J. C. (2007). El daño. Bogotá, D.C.: Universidad Externado de Colombia.

Jaramillo, A. (2018). Principio de responsabilidad de los interventores y supervisores en la contratación pública. [Online]. Bogotá, D.C.: Observatorio Colombiano de Contratación Pública. Disponible en http://www.occp.co/principio-deresponsabilidad-de-los-interventores-y-supervisores-enla-contrataci\%C3\%B3n-p\%C3\%BAblica

Kelsen, H. (1982). Estática Jurídica [Trad. R. Vernengon]. En, H. Kelsen, Teoría Pura del Derecho (pp. 123-200). México, D.F.: Universidad Nacional Autónoma de México.

Luna, F. (2018). El mito del cientificismo en la valoración de la prueba científica. Jurídicas CUC, 14(1), 119-144. http:// dx.doi.org/10.17981/juridcuc.14.1.2018.6

Mazeaud, H., Mazeaud, L., Tunc, A., Capitant, H. y Alcala, L. (2017). Tratado teórico y práctico de la responsabilidad civil delictual y contractual. Buenos Aires: Ediciones Jurídicas Europa-America.

Ordóñez, T. (2007). La Responsabilidad Fiscal en Colombia y la Imposibilidad del Resarcimiento patrimonila. IUSTA, (26), 126-135. https://doi.org/10.15332/s19000448.2007.0026.07 
República de Colombia. Asamblea Constituyente. (1991). Constitución Política. Gaceta Constitucional, (127). Disponible en http://babel.banrepcultural.org/cdm/ref/collection/ p17054coll26/id/3850

República de Colombia. Congreso de la República. (15 de enero de 2018). Por la cual se adicionan, modifican y dictan disposiciones orientadas a fortalecer la contratación public a en colombia, la ley de infraestructura y se dictan otras disposiciones. [Ley 1882]. Diario Oficial: 50.477. Disponible en http://svrpubindc.imprenta.gov.co/diario/

República de Colombia. Congreso de la República. (12 de julio de 2012). Código General del Proceso. [Ley 1564]. DO: 48.489. Disponible en http://svrpubindc.imprenta.gov.co/ diario/

República de Colombia. Congreso de la República. (12 de julio de 2011). Por la cual se dictan normas orientadas a fortalecer los mecanismos de prevención, investigación y sanción de actos de corrupción y la efectividad del control de la gestión pública. [Ley 1474]. DO: 51.478. Disponible en http:// svrpubindc.imprenta.gov.co/diario/

República de Colombia. Congreso de la República. (18 de agosto de 2000). Por la cual se establece el trámite de los procesos de responsabilidad fiscal de competencia de las contralorías.[Ley 610]. DO: 44.133. Disponible en http://svrpubindc.imprenta.gov.co/diario/

República de Colombia. Congreso de la República. (28 de octubre de 1993). Estatuto General de Contratación de la Administración Pública. [Ley 80]. DO: 51.478. Disponible en http://svrpubindc.imprenta.gov.co/diario/

República de Colombia. Congreso de la República. (15 de diciembre de 1975). Por la cual se crea el instituto de mercadeo agropecuario y se determinan sus funciones. [Ley 70]. DO: 17.993. Disponible en http://svrpubindc.imprenta.gov.co/ diario/ 
República de Colombia. Congreso de la República. (19 de julio de 1923). Sobre reorganización de la contabilidad oficial y creación del Departamento de Contraloría. [Ley 42]. DO: 19.129. Disponible en http://svrpubindc.imprenta.gov.co/ diario/

República de Colombia. Congreso de la República. (31 de mayo de 1873). Código Civil Colombiano. [Ley 84]. DO: 2.867. Disponible en http://svrpubindc.imprenta.gov.co/diario/

República de Colombia. Consejo de Estado. (19 de mayo de 2016). Expediente 68001-23-33-000-2013-01024-01. [Sentencia 2013-01024]. Consejero Ponente: María Elizabeth García González. Recuperado de http://www.consejodeestado. gov.co/documentos/boletines/PDF/68001-23-33-000-201301024-01.pdf

República de Colombia. Consejo de Estado. (28 de febrero de 2013). Radicado 25000-23-26-000-2000-00732-01(24266). [Sentencia 2000-00732]. CP: Danilo Rojas Betancourth. Recuperado de http://www.consejodeestado.gov.co/ documentos/boletines/128/S3/25000-23-26-000-200000732-01(24266).pdf

República de Colombia. Consejo de Estado. (26 de agosto de 2004). Espediente 05001-23-31-000-1997-2093 01. [Sentencia 2093]. CP: Gabriel Eduardo Mendoza Martelo. Recuperado de https://www.funcionpublica.gov.co/eva/gestornormativo/norma_pdf.php?i=44886

República de Colombia. Contraloría General de la República (12 de mayo de 2017). Respuesta Solicitud Culpa grave - Detrimento patrimonial y sus consecuencias. [Concepto de la Oficina Jurídica No. 2017EE0038579]. Recuperado de https:// www.contraloria.gov.co/documents/530675/707070/ CGR-OJ-0060-2017.PDF/67a7a4e4-b497-4382-af03cd6e9481e77e?version $=1.0$ 
República de Colombia. Contraloría General de la República. (13 de marzo de 2006). Responsabilidad Fiscal. Detrimento Patrimonial. Falta Disciplinaria. [Concepto 80112 EE15354]. Disponible en https://www.javeriana.edu.co/ personales/hbermude/Novitas94/FileNovitas94/concepto80112ee15354.htm

República de Colombia. Corte Constitucional. (4 de junio de 2014). Expediente D-9929. [Sentencia C-338]. Magistrado Ponente: Alberto Rojas Ríos. Disponible en https://www.corteconstitucional.gov.co/relatoria/2014/C-338-14.htm

República de Colombia. Corte Constitucional. (31 de julio de 2013). Expediente D-9466. [Sentencia C-512]. MP: Mauricio González Cuervo. Disponible en https://www.corteconstitucional.gov.co/RELATORIA/2013/C-512-13.htm

República de Colombia. Corte Constitucional. (9 de mayo de 2007). Expediente D-6536. [Sentencia C-340]. MP: Rodrigo Escobar Gil. Disponible en https://www.corteconstitucional. gov.co/relatoria/2007/C-340-07.htm

República de Colombia. Corte Constitucional. (8 de agosto de 2002). Expediente D-3873. [Sentencia C-619]. MP: Jaime Córdoba Triviño y Rodrigo Escobar Gil. Disponible en https:// www.corteconstitucional.gov.co/relatoria/2002/C-619-02. htm

República de Colombia. Corte Constitucional. (9 de agosto de 2001). Expediente D-3389. [Sentencia C-840]. MP: Jaime Araujo Renteria. Disponible en https://www.corteconstitucional.gov.co/relatoria/2001/c-840-01.htm

República de Colombia. Corte Suprema de Justicia (24 de agosto de 2009). Expediente 11001-3103-038-2001-01054-01. [Sentencia 2001-01054]. MP: William Namén Vargas. Disponible en https:/www.redjurista.com/Documents/ corte_suprema_de_justicia,_sala_de_casacion_civil_e._ no._1054_de_2010.aspx\#/ 
República de Colombia. Presidencia de la República. (23 de mayo de 1932). Por el cual se reforman las leyes orgánicas de la contabilidad oficial de la Nación y del Departamento de Contraloría. [Decreto 911]. DO: 21.997. Disponible en http://svrpubindc.imprenta.gov.co/diario/

Sánchez, J. (2018). Análisis del contrato de interventoría desde la visión de la jurisprudencia colombiana. Cuadernos de la Maestría en Derecho, (6), 175-222. Disponible en https:// revistas.usergioarboleda.edu.co/index.php/Cuadernos/article/view/1008

Santofimio, J. (2007). Tratado de Derecho Administrativo [Tomo I]. Bogotá, D.C.: Externado de Colombia.

Tamayo, J. (2007). Tratado de Responsabilidad Civil [Tomo I]. Bogotá, D.C.: Legis.

* El presente artículo surge del resultado del proyecto de investigación: Prueba del dolo y culpa grave de los interventores contractuales en casos de responsabilidad fiscal: Análisis de los fallos de la Contraloría General de la República -Gerencia Bolívar 2012-2020-. Para obtener el título de Magister en Contratación Estatal de la Universidad de Medellín. Año 2019. 
Luis Carlos Gil Cadavid es Abogado. Especialista en Derecho Administrativo y especialista en Contratación Estatal. Candidato a magister en Contratación Estatal de la Universidad de Medellín (Colombia). Profesional Universitario Grado 01 de la Contraloría General -Gerencia Bolívar-. https://orcid.org/0000-0002-91960730

Uriel Ángel Pérez Márquez es Abogado litigante y consultor especializado. Docente con experiencia en investigación (Corporación Universitaria Rafael Núñez, Universidad Tecnológica de Bolívar, Universidad de San Buenaventura -Seccional Cartagena, Universidad del Sinú -Seccional Cartagena, Universidad del Magdalena, ESAP, Colombia). Tutor temático de maestría en Derecho Penal de la Universidad Sergio Arboleda (Colombia). Conjuez del Tribunal Administrativo de Bolívar (Colombia). Conjuez del Consejo Seccional de la Judicatura de Bolívar. Especialista en Derecho Contencioso Administrativo de la Universidad Externado de Colombia. Especialista en Contratación Estatal de la Universidad de Medellín (Colombia). Estudios de Maestría en Derecho Administrativo (Universidad Externado de Colombia). Candidato a magister en Contratación Estatal (Universidad de Medellín). https:/orcid. org/0000-0002-8393-3476 